\title{
ENCEFALITIS POR EL VIRUS DE HERPES SIMPLE TIPO 2 EN UN PACIENTE ADULTO SANO: UN CASO INUSUAL
}

\author{
Laryssa Alves-de Farias $\mathbb{1}^{1, a}$, Daiana Galvão-Silva $\mathbb{C}^{2, a}$, Cecilia Reyes-Cancino $\mathbb{C}^{3, a}$, \\ Germán Málaga $\oplus^{3,4, b}$ \\ 1 Universidad Católica de Pernambuco (UNICAP), Recife, Brasil. \\ 2 Universidad de Uberaba (UNIUBE), Minas Gerais, Brasil. \\ 3 Universidad Peruana Cayetano Heredia, Lima, Perú. \\ ${ }^{4}$ Hospital Nacional Cayetano Heredia, Lima, Perú. \\ a Médica cirujana; ${ }^{\mathrm{b}}$ médico internista, magister en medicina.
}

\section{RESUMEN}

La infección neurológica por el virus del herpes simple tipo 2 (VHS-2) es responsable de una morbimortalidad significativa que debe ser diagnosticada y tratada lo antes posible. Clásicamente se caracteriza por la tríada de fiebre, cefalea y cambios de comportamiento. La asociación de los síntomas, los resultados de las pruebas de laboratorio y las imágenes son fundamentales para el diagnóstico precoz y el tratamiento inmediato de esta patología, a fin de prevenir que su progresión sea fatal. Presentamos el caso de un paciente varón de 45 años con diagnóstico de encefalitis por VHS-2 después del uso crónico de corticoides. La infección neurológica por VHS-2 en pacientes adultos previamente sanos después del uso crónico de corticoides es extremadamente infrecuente y la asociación no había sido descrita previamente.

Palabras clave: Encefalitis; Infección por el Virus Herpes Simple; Adultos (fuente: DeCS BIREME).

\section{HERPES SIMPLEX VIRUS TYPE 2 ENCEPHALITIS IN A HEALTHY ADULT PATIENT: AN UNUSUAL CASE}

\begin{abstract}
Neurological infection by herpes simplex virus type 2 (HSV-2) is the cause of significant morbidity and mortality; and should be diagnosed and treated as soon as possible. Typically, it is characterized by fever, headache and behavioral changes. Symptoms association, laboratory tests results and diagnostic imaging are essential for early diagnosis and treatment of this disease, in order to prevent its fatal progression. We present the case of a 45-year-old male patient diagnosed with HSV-2 encephalitis due to chronic steroid use. In previously healthy adult patients, neurological HSV-2 infection due to chronic steroid use is extremely rare; and the association has not been previously described.
\end{abstract}

Keywords: Encephalitis; Herpes Simplex; Adults (source: MeSH NLM).

Citar como: Alves-de Farias L, GalvãoSilva D, Reyes-Cancino C, Málaga G. Encefalitis por el virus de herpes simple tipo 2 en un paciente adulto sano: un caso inusual. Rev Peru Med Exp Salud Publica. 2020;37(3):566-70. doi: https://doi. org/10.17843/rpmesp.2020.373.4752

Correspondencia: Germán Málaga Rodríguez; Jirón Las Cantutas 479-2. Casuarinas Sur, Santiago de Surco, Lima, Perú; german.malaga@upch.pe

Recibido: $18 / 08 / 2019$ Aprobado: $17 / 06 / 2020$ En línea: $28 / 07 / 2020$

\section{INTRODUCCIÓN}

La infección neurológica por el virus del herpes simple tipo 2 (VHS-2) es responsable de una morbimortalidad significativa y es una de las pocas infecciones virales con terapia específica y efectiva ${ }^{(1)}$. Se caracteriza clínicamente por un inicio agudo y por la tríada de fiebre, cefalea asociados o no a síntomas neurológicos y cambios de comportamiento, principalmente secundarios a la afectación del lóbulo temporal ${ }^{(2)}$. Aunque el diagnóstico temprano es crítico para la terapia, las secuelas neurológicas son comunes. Ante la sospecha diagnóstica se debe iniciar tratamiento empírico con aciclovir hasta que se realice la confirmación del diagnóstico, dada su baja toxicidad y alta eficacia cuando es administrado tempranamente ${ }^{(3)}$. El diagnóstico de certeza viene dado por la asociación de la reacción en cadena de la polimerasa para virus herpes, la tomografía computarizada, la resonancia magnética, el electroencefalograma y el análisis del líquido cefalorraquídeo ${ }^{(4)}$. 
Se presenta un caso inusual de encefalitis por VHS-2 en un paciente varón de 45 años con síntomas neuropsiquiátricos, VIH negativo, después del uso crónico de corticosteroides, que ingresó en el Hospital Nacional Cayetano Heredia de Perú.

\section{REPORTE DE CASO}

Paciente varón de 45 años, mestizo, casado, natural de Lima, procedente de Chimbote, comerciante, fumador y bebedor social. Niega consumo de drogas ilícitas. Se encuentra en tratamiento diario con prednisona $50 \mathrm{mg}$ desde hace un año en dosis variable (según la activación de lesiones dérmicas faciales), por lo que dos meses antes del ingreso le hicieron el diagnóstico de lupus discoide. No recuerda haber tenido lesiones genitales en el pasado.

Nueve días antes del ingreso el paciente presenta de manera insidiosa fatiga, cefalea moderada, y sensación de alza térmica no cuantificada, asociada a náuseas sin vómitos ni signos de alarma, que disminuyen de manera parcial con paracetamol $1 \mathrm{~g}$ vía oral.

Seis días antes del ingreso se tornó irritable, agresivo, con habla incoherente de manera intermitente. Cinco días antes del ingreso fue internado en un centro privado, donde debido a su agitación psicomotriz se le administró haloperidol $1,5 \mathrm{mg}$ y fue remitido a consulta psiquiátrica.

Dos días antes del ingreso, el paciente es referido al Instituto de Salud Mental Alberto Hurtado-Hideyo-Noguchi, donde fue observado por 24 horas, siendo referido al Hospital Cayetano Heredia para descarte de neurolupus como causa orgánica del trastorno neuropsiquiátrico.

En el examen físico, el paciente se encontraba levemente taquicárdico (FC: $95 \mathrm{lpm}$ ), afebril, en aparente regular estado general, hidratado, no cianótico, ni ictérico, con un IMC de 32,2. Mostraba placas eritemato-violáceas en región malar con descamación superficial, asociado a escasas erosiones con costras y escamas distribuidas en tronco anterior y pos- terior. No se evidenciaron lesiones genitales. Tuvo signo de Nikolsky negativo.

En la evaluación neurológica, el paciente se encontraba despierto, activo, desorientado en espacio. Escala de Glasgow de 14/15 (respuesta verbal: 4), pupilas isocóricas y reactivas. Movilizaba las cuatro extremidades, no presentaba reflejos patológicos y los reflejos osteotendinosos estaban conservados. No tenía rigidez de nuca ni signos meníngeos. La función de los pares craneales estaba conservada y la prueba de Romberg resultó negativa. La memoria de corto plazo y asociativa se encontraban alteradas profundamente, así como incapacidad de abstracción o de realizar operaciones matemáticas simples.

Debido al estado clínico del paciente no se pudo realizar la evaluación psiquiátrica. Se planteó como hipótesis diagnósticas: alteración del estado mental de causa infecciosa (encefalitis viral, meningoencefalitis subaguda por Mycobacterium tuberculosis o Listeria monocytogenes) o alteración del estado mental de causa no infecciosa (neurolupus o encefalitis autoinmune) o encefalopatía aguda de causa metabólica.

$\mathrm{Al}$ ingreso se le realizó una tomografía donde se observó una lesión hipodensa en el hemisferio cerebral izquierdo (Figura 1). La función renal, hepática y el medio interno resultaron sin alteraciones. En la punción lumbar, se obtuvo líquido cefalorraquídeo (LCR) incoloro, trasparente, con recuento de leucocitos de 10 linfo-mononucleares y 5 hematíes. Tinción de gram y tinta china negativas. No se encontró glucosa en LCR, ni presión de apertura.

En el área de emergencia, se le prescribió y administró de forma conjunta: ceftriaxona $4 \mathrm{gr} /$ día $\mathrm{EV}$ en dos dosis, los primeros 3 días; ampicilina 12 gr/día EV en 6 dosis por 8 días y aciclovir $8 \mathrm{mg} / \mathrm{kg} /$ día $\mathrm{EV}$ dividido en tres dosis por 21 días completos.

En el área de hospitalización de medicina interna se realizaron más pruebas de laboratorio: se obtuvieron VDRL y VIH negativos; anticuerpos antinucleares, perfil de anticuerpos contra antígenos extractables del núcleo (ENA) y anticuerpos antineutrófilo citoplasmáticos (ANCA) negativos; complemento normal. Se le realizó un segundo análisis de LCR a las 48 horas de hospitalización, cuyo resultado cito-

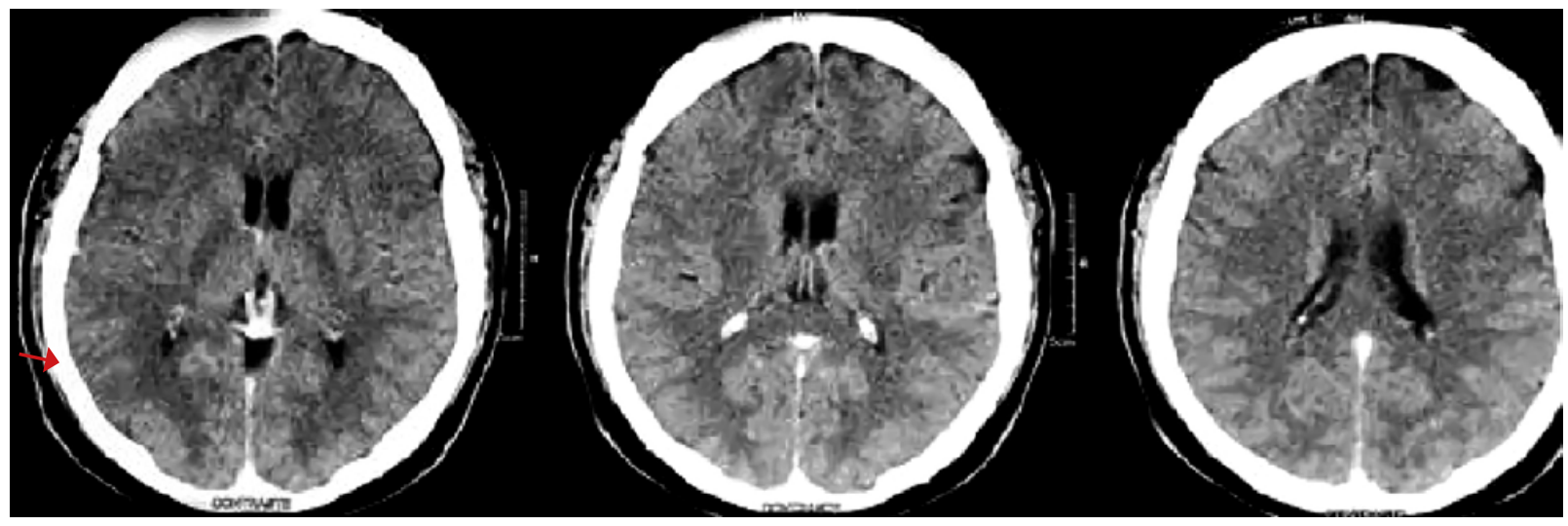

Figura 1. Tomografía Espiral Multicorte cerebral del paciente. Sospecha de una lesión hipodensa en el hemisferio cerebral izquierdo 
lógico y bioquímico fue muy similar al realizado en emergencia, además, se solicitó VDRL y ANA, ambos negativos. Se realizó un panel viral con Entherpex y se detectó material genético del VHS-2. Debido a la agudeza del cuadro (menor de 6 semanas) y a la respuesta favorable con el tratamiento prescrito, no se solicitaron pruebas diagnósticas para descarte de encefalitis autoinmune ${ }^{(6)}$.

A los cuatro días del ingreso, le realizó una resonancia magnética cerebral y una arteriografía, las que no mostraron cambios importantes (Figuras 2 y 3). Tras 25 días de hospitalización y completado el tratamiento antiviral, se procedió al alta hospitalaria, quedando como secuela cierto compromiso de la memoria remota y ansiedad.

El paciente fue seguido en el servicio de neurología hasta un año después y fue dado de alta con recuperación plena de sus funciones mentales superiores. Acudió a una cita de control de dermatología donde se le confirmó el diagnóstico de pénfigo foliáceo, se le redujo la prednisona hasta suspenderla y se le prescribió azatriopina, con lo que se logró controlar las lesiones dérmicas. Ha tenido cinco citas de control en el consultorio de medicina interna, donde refirió síntomas como cefalea y síntomas de trastorno general de ansiedad, sin llegar a desarrollar un cuadro de estrés postraumático. El paciente realiza sus actividades habituales y no refiere secuelas. El trastorno general de ansiedad también cesó.

\section{DISCUSIÓN}

La sospecha clínica de encefalitis viral está basada en la presencia de criterios mayores como alteración del estado mental (definida como alteración del nivel de conciencia, letargia o desordenes neuropsiquiátricos) de duración mayor a 24 horas, después de haber descartado el diagnóstico diferencial $^{(1,5)}$.

Los virus del herpes simple 1 y 2 infectan las células de la mucosa y luego establecen una infección latente de por vida en la inervación de los ganglios sensoriales y autónomos cerca del sitio de la infección. En adultos inmunocompetentes, el VHS-2 generalmente causa una enfermedad genital no complicada, sin embargo, en el caso de nuestro paciente

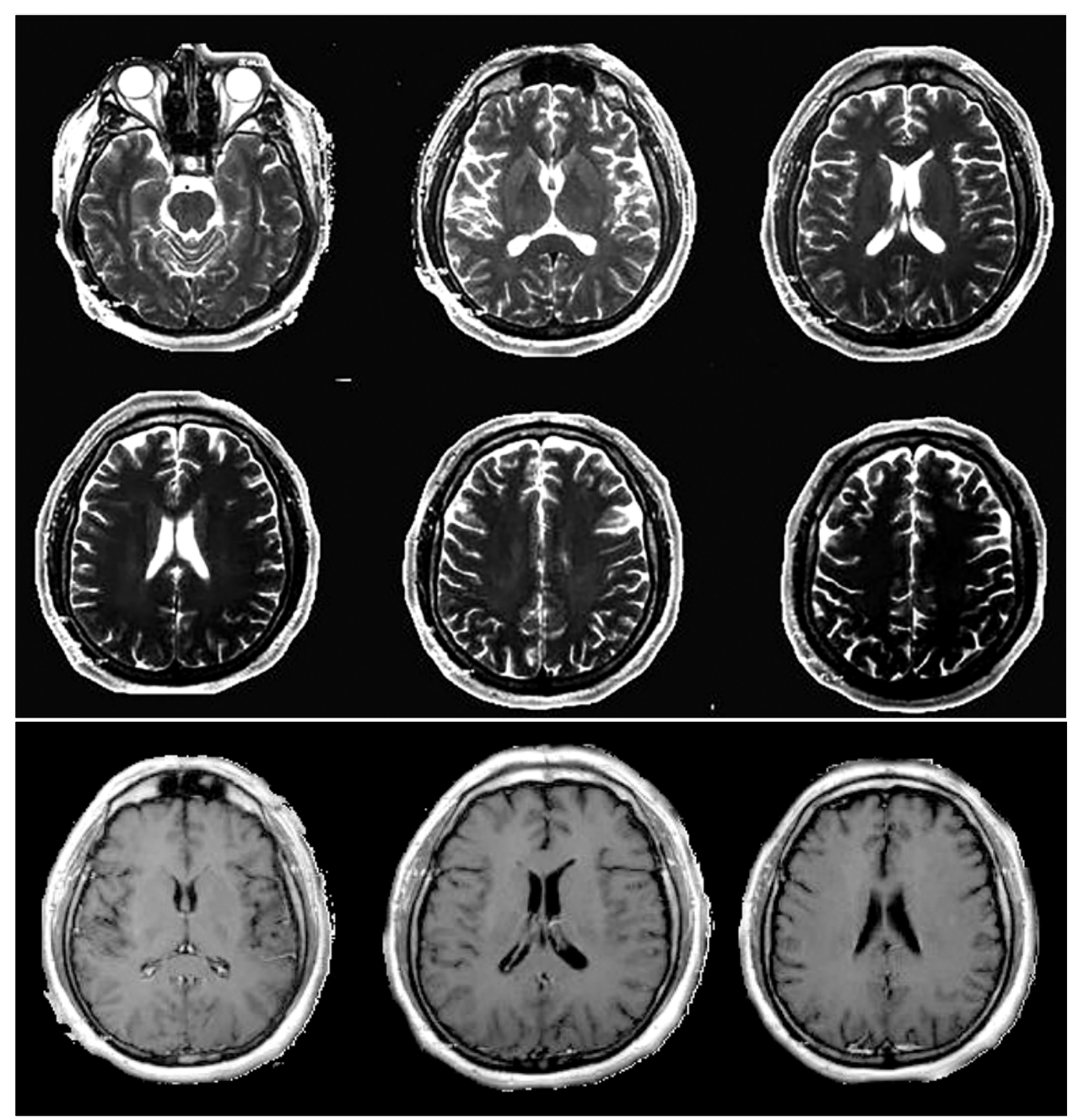

Figura 2. Resonancia magnética cerebral del paciente. No se muestran cambios estructurales ni lesiones significativas 


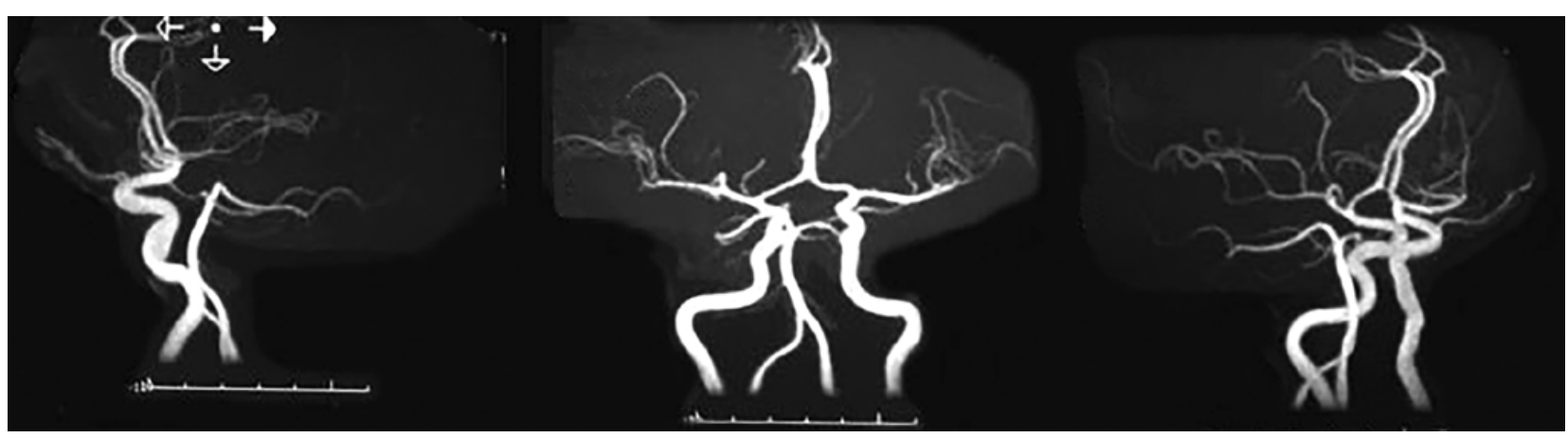

Figura 3. Angiografía cerebral del paciente. No se muestran cambios estructurales ni lesiones significativas

no se registró antecedente clínico ni evidencia en el examen físico. No hemos hallado en la literatura, la frecuencia de ausencia de lesiones con afección del sistema nervioso central. Sin embargo, se describen algunos casos en los que se puede afectar al sistema nervioso, con manifestaciones clínicas como meningitis aséptica autolimitada, mielitis radicular $y$, raras veces, encefalitis ${ }^{(6)}$.

La encefalitis por VHS-2 en adultos es extremadamente infrecuente representando menos del $2 \%$ de todos los casos de encefalitis por herpes simple ${ }^{(6)}$. El neurotropismo viral afecta a las células gliales, causando necrosis hemorrágica principalmente en los lóbulos temporales ${ }^{(7)}$. Los factores del hospedero, como la edad y el nivel de inmunocompetencia son los principales determinantes de la enfermedad, aunque también debe tenerse en cuenta la variabilidad de la neurovirulencia del virus del herpes ${ }^{(8)}$.

Aunque el pronóstico de la encefalitis por herpes simple ha mejorado drásticamente desde la disponibilidad de la terapia antiviral, las secuelas en los pacientes supervivientes pueden incluir déficits neurológicos, convulsiones y disfunciones neuropsicológicas que perjudican en gran medida la calidad de vida ${ }^{(9)}$. El retraso de 48 horas o más al inicio del tratamiento con aciclovir se asocia con un peor pronóstico ${ }^{(8)}$.

Estudios actuales sugieren que los receptores de epinefrina y corticosterona, expresados diferencialmente en las neuronas sensoriales y simpáticas, modulan directamente una potencial infección por VHS-1 o VHS-2, a diferencia de lo que se creía, que era a través de sus efectos en el sistema inmunológico ${ }^{(6)}$. Además, la inmunidad mediada por las células $\mathrm{T}$ es esencial para el control del VHS, por lo tanto, los pacientes inmunodeprimidos, como los receptores de trasplante de órganos que reciben quimioterapia, tienen un mayor riesgo de desarrollar una infección cerebral oportunista grave ${ }^{(10)}$.

En el caso de nuestro paciente, se plantea que la inmunosupresión causada por el uso prolongado de prednisona para el tratamiento de lupus discoide, que luego se confirmó que era un pénfigo foliáceo, ha contribuido de manera decisiva en el desarrollo de la infección neurológica. No hemos hallado reportes en la literatura que asocien la encefalitis por VHS-2 en personas sanas con el uso previo de corticoides.
Los casos descritos son pacientes con diagnóstico de cáncer y en quimioterapia o en cráneoradioterapia ${ }^{(11,12)}$. De este modo, nuestro reporte resulta ser particular, pues se trata de un paciente sin patología sistémica o debilitante demostrada y cuyo único factor de riesgo fue el uso crónico de corticoides, asociación que, hasta donde hemos podido indagar, no ha sido reportada en la literatura médica con anterioridad.

En cuanto a los exámenes complementarios, la tomografía computarizada no es muy útil para el diagnóstico, excepto para excluir otras patologías y para garantizar que la extracción de la muestra de LCR sea segura, excluyendo los signos de hipertensión intracraneal ${ }^{(13)}$. La resonancia magnética puede mostrar cambios típicos en el lóbulo temporal, pero puede ser normal al comienzo de la enfermedad. El diagnóstico de encefalitis herpética generalmente se basa en la presentación típica y en la presencia de ADN del VHS en las muestras de $\mathrm{LCR}^{(14)}$. En nuestro paciente, se detectó la presencia de ADN con la prueba de Entherpex, que permite detectar cantidades mínimas de ADN; además, al utilizar la secuencia correspondiente de una región dentro del genoma vírico y las sondas de captura específicas para cada virus de tipo herpes y enterovirus, ofrece una sensibilidad, especificidad, valor predictivo positivo y negativo de 98,3\%, 99,4\%, 95,2 y $100 \%$, respectivamente, para el VHS2 ${ }^{(15)}$.

La evidencia actual demuestra que el tratamiento con aciclovir es seguro y efectivo, con casos raros de resistencia y reacciones adversas. Después de la incorporación intracelular, el aciclovir se convierte en monofosfato de aciclovir, sin embargo, este paso no ocurre en un grado significativo en las células no infectadas y, por lo tanto, confiere especificidad a la actividad del fármaco ${ }^{(16)}$. Por otro lado, debido a la posibilidad de nefropatía por cristaluria asociada a aciclovir, se recomienda mantener una hidratación venosa adecuada durante el tratamiento. Cabe mencionar que, incluso con un tratamiento temprano, la mortalidad puede alcanzar al $20 \%$ de todos los casos, y menos del $10 \%$ de los pacientes sobrevivientes carecen de secuelas neurológicas o déficits cognitivos ${ }^{(1)}$.

El resultado satisfactorio muestra que el inicio oportuno del tratamiento antiviral con aciclovir ante un cuadro clínico 
de encefalitis herpética disminuye las tasas de morbimortalidad, evita las secuelas graves y conduce a una rápida reversión de la enfermedad. En las afecciones neuropsiquiátricas agudas, se enfatiza la importancia de excluir causas orgánicas, particularmente infecciosas, para prevenir a la persona afectada de potenciales y deletéreas secuelas que, de presentarse, afectarían se manera importante la funcionalidad y calidad de vida.

La infección neurológica por VHS-2 en pacientes adultos es extremadamente infrecuente y sus mecanismos aún no se comprenden del todo, pero puede ocurrir, como en el caso reportado, en un paciente previamente sano después del uso crónico de corticoides. Sin embargo, la baja frecuencia del VHS-2, como agente causal de infecciones en el sistema nervioso central ${ }^{(4)}$, así como la posibilidad de presentar cuadros de encefalitis incluso en ausencia de lesiones genitales, hace que la sospecha clínica sea muy limitada, por lo que, ante la

\section{REFERENCIAS BIBLIOGRÁFICAS}

1. Whitley RJ. Herpes Simplex Virus Infections of the Central Nervous System. Continuum (Minneap Minn). 2015;21(6 Neuroinfectious Disease):1704-13. doi: 10.1212/CON.0000000000000243.

2. Berger A, Shahar T, Margalit N. Herpes Simplex Type 2 Encephalitis After Craniotomy: Case Report and Literature Review. World Neurosurg. 2016;88:691.e9-691.e12. doi: 10.1016/j.wneu.2015.11.101.

3. Ellul M, Solomon T. Acute encephalitis-diagnosis and management. Clin Med (Lond). 2018;18(2):155-9. doi: 10.7861/clinmedicine.18-2-155.

4. Graus F, Titulaer MJ, Balu R, Benseler S, Bien CG, Cellucci T, et al. A clinical approach to diagnosis of autoimmune encephalitis. Lancet Neurol. 2016;15(4):391-404. doi: 10.1016/S1474-4422(15)00401-9.

5. Venkatesan A, Tunkel AR, Bloch KC, Lauring AS, Sejvar J, Bitnun A, et al. Case definitions, diagnostic algorithms, and priorities in encephalitis: consensus statement of the international encephalitis consortium. Clin Infect Dis. 2013;57(8):1114-1128. doi: 10.1093/cid/cit458.

6. Ives AM, Bertkeb AS. Stress Hormones Epinephrine and Corticosterone Selectively Modulate Herpes Simplex Virus 1 (HSV-1) and HSV-2 Productive Infections in Adult Sympathetic, but Not Sensory, Neurons. J Virol. 2017;91(13):e00582-17. doi: 10.1128/JVI.00582-17.

7. Puccioni-Sohler M. Encefalite Viral. In: Joaquim Pereira Brasil Neto; Osvaldo M. Takayanagui. (Org.). Tratado de Neurologia da Academia Brasileira de Neurologia. 1ed. Rio de Janeiro: Elsevier Editor. 2013;84:742-47.

8. Kennedy PGE, Steiner I. Recent Issues in Herpes Simplex Encephalitis. J Neurovirol. 2013;19(4):346-50. doi: 10.1007/s13365-013-0178-6.

9. Saito M, Kiyozaki H, Obitsu T, Imoto H, Taniyama Y, Takata O, et al. Herpes simplex virus-1 encephalitis induced by chemoradiotherapy sospecha de encefalitis viral y teniendo en cuenta que por clínica y laboratorio es muy difícil distinguir entre los diferentes tipos de encefalitis, se debe administrar medicación endovenosa (aciclovir) en forma empírica tan pronto como sea posible, tratamiento que puede preservar la vida y funcionalidad del paciente ${ }^{(16)}$ y luego hacer la confirmación diagnóstica con la detección de material genético del virus causante ${ }^{(15)}$.

Contribuciones de autoría: LAF, DGC y GMR participaron en la concepción del artículo, mientras que CRC participó en la recolección de datos y en la redacción. Todos aprobaron la versión final.

Financiamiento: Autofinanciado.

Conflictos de interés: Los autores declaran no tener conflictos de interés. Se contó con el consentimiento informado del paciente para la publicación de su caso.

Consideraciones éticas: Se contó con el consentimiento informado del paciente para la publicación de su caso. and steroids in an esophageal cancer patient: a case report. BMC Cancer. 2016;16:233. doi: 10.1186/s12885-016-2255-8.

10. Pagliano P, Ascione T, Carleo MA, Boccia G, De Caro F, Tortora F. HIV positive patient with HSV-2 encephalitis: case report. Infez Med. 2016;24(3):245-9.

11. Gaber JJ, Rosenblum MK, De Angelis LM. Herpes simplex encephalitis in patients with cancer. J Neurooncol. 2011;105(2):415-21. doi: 10.1007/s11060-011-0609-2.

12. Ben-Hur T, Cialic R, Itzik A, Barak O, Yirmiya R, Weidenfeld J. A Novel Permissive Role for Glucocorticoids in Induction of febrile and behavioral Signs of Experimental Herpes Simples Virus Encephalitis. Neuroscience. 2001; 108(1):119-27.

13. Urban PP, Jöhnck W, Pohlmann C, Marrakchi S, Brüning R. Reversible progressive cognitive decline due to herpes simplex type 2 e4cephalitis with normal MR imaging. J Neurol. 2008;255(12):1975-7. doi: 10.1007/ s00415-008-0022-8.

14. Cook M, Koehn T, Simmons D, Frattalone A. A Rare Case of Herpes Simplex Virus Type 2 Encephalitis in an Immunocompetent Adult (P5.340). Neurology. 2018; 90:340-5.

15. Leveque N, Van Haecke A, Renois F, Boutolleau D, Talmud D, Andreoletti L. Rapid virological diagnosis of central nervous system infections by use of a multiplex reverse transcription-PCR DNA microarray. J Clin Microbiol. 2011;49(11):3874-79. doi: 10.1128/JCM.01214-11.

16. Ogura H, Fukae J, Kimura S, Aoki M, Nabeshima K, Tsuboi Y. Acyclovir resistant acute herpes simplex encephalitis associated with acute retinal necrosis: A case report and review of the literature. Rinsho Shinkeigaku. 2017;57(5):230-3. doi: 10.5692/clinicalneurol.cn-000959. 